\title{
INTERACTION BETWEEN TEACHER AND PUPIL AND ITS INFLUENCE ON THE PERCEIVED CLOSENESS OF PUPILS
}

\author{
Renáta Matušů \\ Faculty of Humanities, Tomas Bata University in Zlin (Czech Republic)
}

\begin{abstract}
The paper deals with the relationship between teacher and pupil in a school environment. The first part is focused on the theoretical framework which defines the specifics of the asymmetric interaction between the two main subjects of the education process. Research of the teacher's immediacy and perceived closeness is evaluated in this context. These are important aspects that seem to be directly reflected in student's learning and the classroom climate. The second part presents the results of a qualitative study which aimed to analyze the interactions in the relationship between teacher and pupil, their impact and influence on the perceived closeness of pupils. Narrative interviews with humanities students and their analysis identified several aspects in the relationship between teacher and pupil. It seems that relations with teachers are reflected in students' lives and their attitudes towards themselves, authority and education.
\end{abstract}

Keywords: Perceived closeness, pupil, relationship, school environment, teacher immediacy.

\section{Introduction}

For the most part, the educational process arises from the social interaction of at least two entities and takes place within interpersonal relationships. The importance of relationships and interactions in teaching is supported by a social constructivist theory that emphasizes the irreplaceable role of social interaction in building knowledge (Vygotsky, 1978). The whole educational experience can be shaped by the quality of the relationship to a great extent, and therefore the processes of interaction and communication are the cornerstones supporting or hindering the motivation and learning of pupils (Koca, 2016).

Several types of interactions are observed in or outside the school environment. In terms of the positions and roles of entities in the interaction, we distinguish symmetric and asymmetric interactions (Gavora, 2005; Kumpulainen, Wray, 2012). Typically, the symmetric form of interaction occurs between pupils where their positions are equivalent. However, as a formal social institution, the school has a set of rules that also include the positions and roles of participants in the learning process which are asymmetric due to the degree of responsibility and authority of individuals in the institution. In the context of the classroom, an asymmetric interaction occurs in the teacher-pupil relationship where the teacher is superior to the pupils and is allowed to determine the form of teaching and to decide on matters in the classroom. Many experts agree that the interaction between teacher and pupil, pupils or class is a specific type of human action and influence (Haffen et al., 2014, Hurst, Wallace \& Nixon, 2013; Gavora, 2005). Nelešovská (2001) provides details on this claim, stating that in addition to psychological and social aspects, teacher-pupil interactions also include pedagogical aspects, where the pupil is influenced not only by the teacher's knowledge or experience but also by their personality, approach to pupils, interests, character qualities, way of acting or speaking.

In this context, the asymmetry of this relationship stems mainly from the formal aspect of teaching, which is established by the School Rules and the School Legislative Framework. Despite that, informal aspects beyond School Rules and education, in general, are reflected in the relationship. One of these aspects is the degree of perceived closeness, known as the teacher immediacy. The concept of teacher immediacy comes from studies of implicit communication by social psychologist Albert Mehrabian (1969; 1971), who described a communication behaviour enhancing the sense of closeness in human interaction. He coined the term "immediacy behaviour" and based it on the principle of approach avoidance. According to him, people are more intensely and more often involved in interactions with people whom they regard as sympathetic and with whom they experience a higher degree of closeness. 
Conversely, people have an evasive tendency to interact with people with a low degree of closeness between interaction participants. In the educational environment, from the perspective of instructional communication, teacher immediacy can be defined as behaviour including verbal and nonverbal communication stimuli which provide a sense of proximity and reduce the perception of the psychological distance between the teacher and students or pupils (Zhang \& Witt, 2016). In simple terms, it encompasses expressions of affection; teachers show that they like their students (Richmond \& McCroskey, 2000). Traditionally, teacher immediacy is transmitted non-verbally through smile, relaxed posture inclined towards the pupils, seeking eye contact, or variations in voice (Gorham, 1988). Conversely, if the teacher neglects eye contact, uses monotonous voice, does not smile, leans away from students, and does not show enough warmth in general, the development of a positive relationship between the teacher and a pupil is probably impossible. Verbal immediacy is manifested, for example, by addressing the pupil by their name, using the collective pronouns ("our", "we"), verbal empathy, talking to pupils about topics selected by the pupils or sharing the teacher's personal experience (Gorham, 1988).

Research suggests that a higher level of immediacy affects both the affective aspects of learning and cognitive learning (Richmond, Gorham \& McCroskey, 1987; Gorham, 1988; Rodriguez, Plax \& Kearney, 1996; Zhang \& Oetzel, 2006). It also encourages participation, engagement, willingness to communicate or meet teacher's requirements (Manzel \& Carrel, 1999; Burroughs, 2007; Robert \& Friedman, 2013). At the same time, it can act as a neutralizing variable that can compensate for occasional mistakes in teacher's behaviour (Kearney et al, 1988; Thweatt \& McCroskey, 1998; Mottet et al., 2006).

However, all these studies are based on the claim that there are patterns of teacher behaviour that are stable over time. In addition, research concepts are mainly based on quantitative research which, even though it results in new knowledge, is considerably limited by such framing. The idea of stable manifestations of teacher immediacy cannot be conclusively refuted, but it is also necessary to consider whether situational influences affect the perception of proximity. In this context, we want to research: How can the interaction between the teacher and the pupil influence the perceived closeness of the pupil?

\section{Methods}

This research employed methods of qualitative research for the purpose of the research questions. First, narrative interviews were conducted with seven students of humanities; five women and two men. All participants attended regular state primary schools. We chose the narrative conversations deliberately because we assumed that the timeline can be followed retrospectively in order to analyze interactions and their influence on the relationship and perceived proximity. This prediction was confirmed and rich data was obtained for analysis and open coding.

The next part presents the results of the analysis. For purposes of data transparency, the results are complemented by the participants' original statement.

\section{Results}

Teacher-pupil interactions seem to take place in relationships that are perceived as positive, negative or neutral. Those can be either stable or variable. Let's take a closer look at the different types of relationships and the interactions of the two entities in the educational process.

\subsection{Interaction and teacher immediacy in stable relationships}

During school attendance, the participants and experienced stable, constant relationships with their teachers. Stability is supported in particular by established patterns of behaviour employed by the teacher at school. One of the participants literally said: "He acted the same all the time. At no point did he change anything, he applied his approach to everyone and in all circumstances". Behaviour may be closely linked to teacher's personality traits which, according to the participants, played a dominant role, e.g. "for some teachers it was the same for the whole four years, it was clearly given by their nature" or "she had such a cold, dominant nature and that's how she has been treating us the whole time."

3.1.1. Positive, neutral and negative perception of a relationship. Positively perceived relationship shows the highest degree of perceived closeness. The pupil classifies the teacher as their favourite in the early stages of the relationship and this preference lasts throughout their school attendance. "From the very beginning, she was so kind, often talking to us and asking us how we were. I loved that about her". This stability provided the students with a sense of security and safety, so it was in this type of relationship where they most often said: "when I did not know what to do, I asked her because she was the closest to me and I was sure she would not refuse me". In return, the students tried to be 
accommodating to these teachers and tried to meet their demands. This can be supported by the statement "when she asked us to behave nicely towards a certain unpopular teacher, I took her words seriously".

The second type of relation, perceived as neutrally stable, represents the middle ground between the two relational poles. It is a type of relationship that does not provide closeness between the actors of interaction. Teachers do not create or make use of situations that could shape and develop teaching on the interpersonal level. Participants mostly acknowledged teacher's lessons taught in an interesting manner but also said that they did not perceive such a teacher as significant to them. "He wasn't a bad teacher, but he wasn't anyone to me, just someone without a face, an unknown person, he was just teaching..." or "Her lessons were interesting, she could narrate very well, but the teacher wasn't interested in anything else, so there was just emptiness between us".

In a negatively perceived relationship are characterised by a high degree of tension and a low level of teacher immediacy. Inappropriate behaviour of both the teacher and the pupil may occur and we can observe delaying tactics and avoiding interaction with the teacher. A relationship assessed as negative from the pupil's point of view begins with minor negative stimuli that interact with a persistent negative assessment of the teacher and interaction with them.

Interactions in this relationship overreach into a personal level, making them more sensitive for the pupils. Specifically, Participant stated: "I hear as if it was today how he always said that I was useless and I'll end up in a factory as a worker and he mocked me when I submitted my high school application". These interactions may have a stronger impact on the pupils, for example, "I have often struggled with the feeling of inferiority" or "because of that, I do not trust teachers anymore", "it's actually because of her that I feel bad about school".

3.1.2. Confirmation. Although this is an interpersonal plane where no major changes occur, the interactions still take place within situations. In this context, we have identified s phenomenon that we call confirmation. The participants stated that at least one significant situation has emerged in a stable relationship that has confirmed the relationship between the teacher and the pupil. In some cases, a subjective deepening of the perceived closeness occurred at the same time. This fact is reflected in the following statement: "At that moment I was expecting him to react negatively, whereas she accepted the situation perfectly. That's how she won me over even more than before. I thought she was an angel, not a human". In another case, the confirmation may occur in a negatively perceived relationship. "He didn't have to deal with it in such radical manner. He even said he didn't have to, but he went ahead and made it an issue. By doing that, he definitely changed my perception of him for the worse".

\subsection{Interaction and teacher immediacy in variable relationships}

The results suggest that teacher immediacy may be subject to situational influences that affect perceived closeness through interaction with the pupil. Within that context, we have identified a model (Fig. 1) that illustrates how relationships, interactions, and perceptions of closeness work.

3.2.1. A model of changes in relationships and perceived closeness. Figure 1 shows the changes in relationships and interactions related to perceived closeness. Every social interaction occurs within a certain relationship that seems to be evaluated on the scale of negative - neutral - positive. In variable relationships, the initially perceived relationship plays a crucial role as it can determine the degree of closeness that will be perceived after a breaking point.

A breaking point is a situation in which an interaction had a radical impact on the perceived closeness and understanding of the relationship. Interactions leading to increased perceived closeness can manifest themselves in different forms on the teacher's part. Usually, the teacher acted "unexpectedly" better than predicted.

For example, the statements included: "I was quite surprised that she was defending me", "I did not expect that he would notice and ask what was going on", "I did not believe that he would ever acknowledge that I had done it and gotten better". In the wake of this interaction follows a more intense experience of closeness, which in the case of an initially neutral relationship has a very positive impact on the transformation of the relationship and its further development. Whether the higher perceived closeness will last long will be determined by following interactions that will either confirm or disprove the state.

Reduction the closeness where the pupil grows more distant follow from deeply disruptive interactions between the teacher and the pupil. Participants reported that certain teacher behaviours have irreparably affected their ongoing coexistence in the school environment, for example perception of betrayal by the teacher, disregarding the pupil, failure to provide help, teacher's hostile behaviour, or false accusation. This point shows that teacher-pupil relationships are fragile and can have an impact on pupils attitude toward teachers, learning, and authority in general. 
"I was never good at math, but I thought I'd just learn for the test and make the teacher happy as well. I passed the test with great success but the teacher did not believe me that I wrote it. I was really upset by her suspicions and that was it for me - after that, I stopped caring about her and also about math".

In these cases, however, there may still be a turning point when a situation neutralizing the negativity of the previous interaction occurs. This compensation is not so strong that it could completely erase the pupil's previous negative experience. However, it can increase the level of perceived closeness in cases where the teacher increases their manifestations of immediacy.

"When we were dealing with truancy issues, I thought she would scream and threaten, but she acted in a completely different manner. When we came to her office, she was nice, and she was very interested in what motivated us to do that. She listened to us and accepted the reasons. I had the feeling that she cared about us. This improved my perception of her, despite what happened."

Most of the participants stated that after these turning point interactions, they changed their opinion of the teacher, made more effort to understand and explain their previous behaviour as "everyone can make a mistake". However, none of the investigated cases has completely inverted the polarity of a negatively perceived teacher relationship. It is, however, appropriate to assume that this could happen, especially if we consider the influence of social perception which is subject to errors such as Halo effect, stereotypes.

Figure 1. A model of changes in relationships and interactions related to perceived closeness.

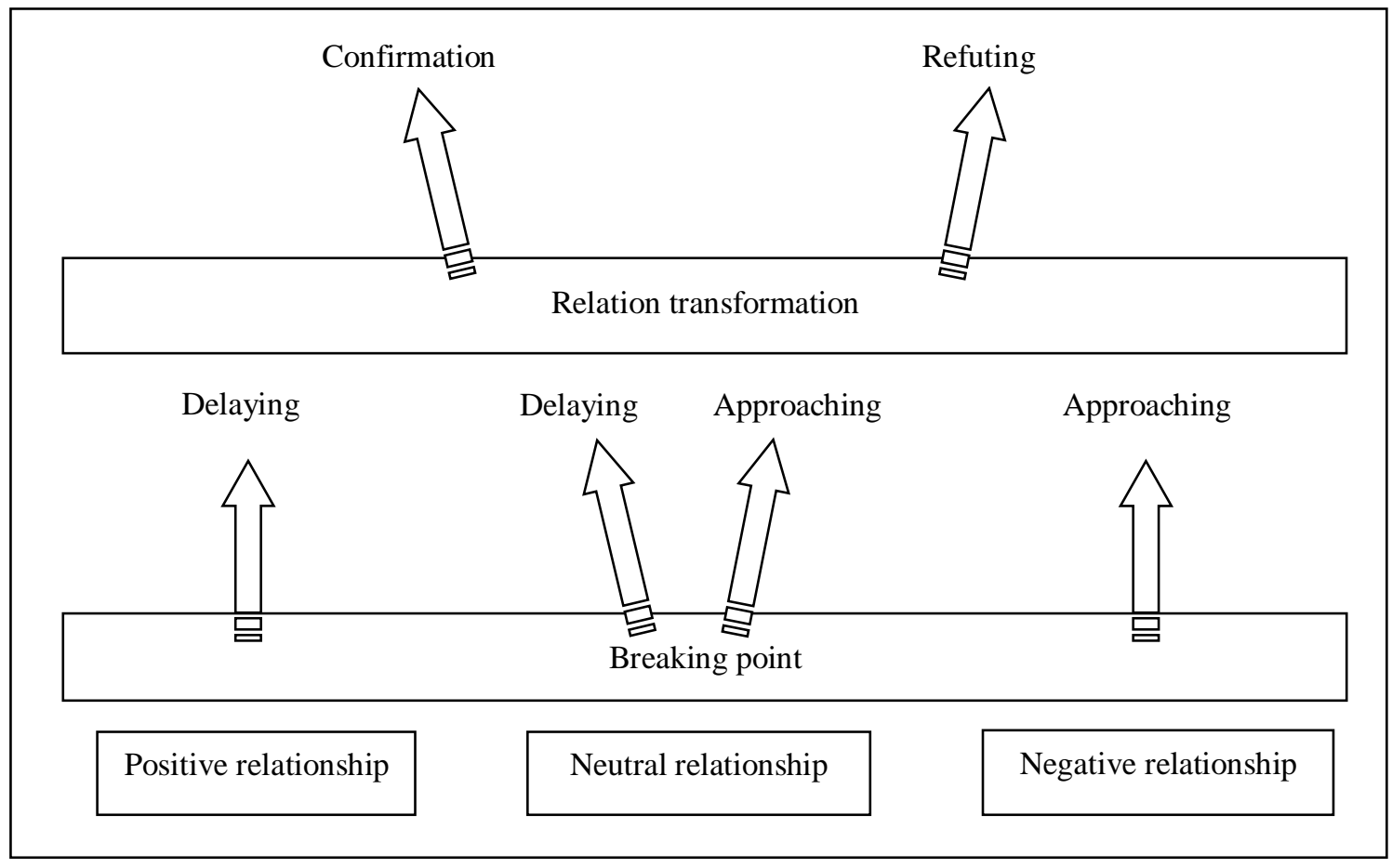

\section{Discussion}

The results of the study suggest that immediacy, relationships and interactions inseparably intertwined and require a holistic approach. It is probable that the degree of perceived closeness can be assumed based on how pupils evaluate their relationships with teachers. Relationships with teachers can be reassessed based on situations and interactions that can be seen as a breaking point. This would mean that the degree of perceived closeness follows the dynamics of teacher-pupil relationships and is not necessarily stable. We consider significant the finding that, despite a negative assessment of the pupil's relationship with a teacher, it can be turned by increasing teacher immediacy and other positive components of teacher's communication strategies.

These results are consistent with theories of teacher immediacy. For example, we have identified situations where, by failing to confirm expectations, the effect of the situation on the pupil was increased. This is explained by the theory of expectancy violations (Burdoon, 2015; 1988) which emphasizes this phenomenon. Approach - avoidance of pupils was also reflected here, depending on the perceived degree 
of closeness. Furthermore, we must point out that a turning point can neutralize negative perceptions of a teacher. Similar results appear in quantitative studies (Thweatt \& McCroskey, 1998; Mottet et al., 2006). These findings stem from students' retrospective views, from their subjective view of the interactions and behaviour of teachers at primary school. Despite its limitations, qualitative research offers a new perspective in terms of changes in relationships and perception of the closeness of pupils. Given that the relationship between the teacher and the pupil is not only asymmetric but has also proven to be informal, shaped by personal views, these aspects deserve examination and determination of their role in the interaction but also in the pupil's learning and motivation.

\section{References}

Burdoon, J. K. (2015) Expectancy violations theory In Berger et al. The International Encyclopedia of Interpersonal Communication, First Edition, Wiley-Blackwell.

Burgoon, J. K., \& Hale, J. L. (1988). Nonverbal expectancy violations: Model elaboration and application to immediacy behaviors. Communication Monographs, 55(1), 58-79.

Burroughs, N.F. (2007) A Reinvestigation of the Relationship of Teacher Nonverbal Immediacy and Student Compliance-Resistance with Learning, Communication Education, 56, 453-475. https://doi.org/10.1080/03634520701530896

Gavora, P. (2005). Teacher and pupils in communication. Brno: Paido.

Gorham J. (1988). The relationship between verbal teacher immediacy behaviors and student learning. Communication Education, 37 (1), 40-53.

Hurst, B., Wallace, R., \& Nixon, S. B. (2013). The Impact of Social Interaction on Student Learning.Reading Horizons, 52(4), 24-33. $\quad$ Retrieved from https://scholarworks.wmich.edu/reading_horizons/vol52/iss4/5

Hafen Ch A. , et al. (2015) Teaching Through Interactions in Secondary School Classrooms: Revisiting the Factor Structure and Practical Application of the Classroom Assessment Scoring System-Secondary. J Early Adolesc., 35(5-6): 651-680.

Kearney, P., Plax, T. G., Smith, V. R., \& Sorensen, G. (1988). Effects of teacher immediacy and strategy type on college student resistance to on-task demands. Communication Education, 37(1), 54-67. http://dx.doi.org/10.1080/03634528809378703

Koca, F. (2016) Motivation to Learn and Teacher-Student Relationship. Journal of International Education and Leadership, 6(2), 1-20.

Kumpulainen,K.\& Wray, D. (2012) Classroom Interaction and Social Learning: From Theory to Practice. Psychology Press.

Mehrabian, A. (1971). Verbal and nonverbal interaction of strangers in a waiting situation. Journal of Experimental Research in Personality, 5, 127-138.

Menzel, K., \& Carrell, L. (1999). The impact of gender and immediacy on willingness to talk and perceived learning. Communication Education, 48, 31-40. doi:10.1080/0363452990937915

Mottet T. P. et al. (2006) Testing the Neutralizing Effect of Instructor Immediacy on Student Course Workload Expectancy Violations and Tolerance for Instructor Unavailability, Communication Education, 55:2, 147-166, DOI: 10.1080/03634520600565886

Roberts A.\& Friedman D. R. (2013) The Impact of Teacher Immediacy on Student Participation: An Objective Cross-Disciplinary Examination, 25(1), 38-46.

Rodriguez, J. I., Plax, T. G., \& Kearney, P. (1996). Clarifying the relationship between teacher nonverbal immediacy and student cognitive learning: Affective learning as the central causal mediator. Communication Education, 45, 293-305.

Richmond, V., \& McCroskey, J. (2000). Nonverbal Behavior in Interpersonal Relations. Boston: Allyn $\&$ Bacon.

Richmond, V. P., Gorham, J. S., \& McCroskey, J. C. (1987). The relationship between selected immediacy behaviors and cognitive learning. In M. McLaughlin (Ed.), Communication yearbook 10, Beverly Hills, CA: Sage, 574-590.

Thweatt, S. K. \& McCroskey J. C. (1998) The impact of teacher immediacy and misbehaviors on teacher credibility, Communication Education, 47(4), 348-358.

Vygotsky, L. S. (1978). Mind in Society: the Development of Higher Psychological Processes. Cambridge, MA: Harvard University Press.

Zhang, Q. \& Witt P. L. (2016) Instructor immediacy In P. L. Witt (Ed) Communication and learning. Berlin: De Gruyter Mouton, 157-180. 